\title{
Supercritical fluid extraction of pesticides in sediment from the Okavango Delta, Botswana, and determination by gas chromatography with electron capture detection (GC-ECD) and mass spectrometry (GC-MS)
}

\author{
Lesego C Mmualefe ${ }^{1 *}$, Nelson Torto', Philippa Huntsman-Mapila² and Bontle Mbongwe ${ }^{3}$ \\ ${ }^{1}$ University of Botswana, Dept. of Chemistry, Private Bag UB00704, Gaborone, Botswana \\ ${ }^{2}$ University of Botswana, Harry Oppenheimer Okavango Research Centre, Private Bag 285, Maun, Botswana \\ ${ }^{3}$ University of Botswana, Dept. of Environmental Science, Private Bag UB00704, Gaborone, Botswana
}

\begin{abstract}
The study reports supercritical fluid extraction (SFE) of pesticides in sediment samples from the Okavango Delta, the headwaters of which originate from Angola and traverse through Namibia into Botswana. An acetone modifier and fractional extraction by pressure ramping gave recoveries ranging from 55 to $86 \%$ for the 15 pesticides studied. Hexachlorobenzene (HCB), aldrin and 4, 4-dichlorodiphenyltrichloroethane (4, 4'-DDT) were identified at concentration ranges of 1.1 to $30.3,0.5$ to 15.2 and 1.4 to $55.4 \mu \mathrm{g} / \mathrm{g}$, respectively by gas chromatography with electron capture detection (GC-ECD) and were unequivocally confirmed by gas chromatography time-of-flight mass spectrometry (GC-ToF-MS). The study indicated an increase of pesticide concentrations in the direction of water flow from the Panhandle (point of entry) to the lower delta. The results show that there are ramifications associated with activities either upstream or downstream; hence close monitoring is required for the long-term preservation of the delta.
\end{abstract}

Keywords: organochlorine pesticides; sample preparation; modifier; static extraction; dynamic extraction; fractional extraction.

\section{Introduction}

Aquatic environmental sediments, depending on their chemical composition and adsorption characteristics, have a high accumulation capacity for both inorganic and organic contaminants (Guevara-Riba et al., 2006). Organochlorine pesticides (OCPs) such as DDT are an important group of contaminants that have caused worldwide concern as toxic environmental contaminants (Zhao et al., 2007). Their hydrophobicity and persistence cause OCPs to be readily scavenged from the water through sorption onto suspended material, subsequently becoming part of the sediment. However, changes in environmental conditions may lead to the release of contaminants back into the aquatic system thus making sediments a possible source of exposure to aquatic organisms (Delistraty and Yokel, 2007). The presence of contaminants at low concentrations as well as the chemical complexity of matrices such as soil, sediment and biota calls for preliminary treatment of environmental samples. This procedure is normally referred to as sample handling and includes extraction, clean-up and pre-concentration of the sample (Santos and Galceran, 2002; Gabaldón et al., 2007).

Limitations encountered in classical sample handling techniques such as Soxhlet extraction have been overcome by employing modern techniques that are faster and environmentfriendly such as supercritical fluid extraction (SFE) (Rodil et al., 2007). SFE has gained increased attention as an alternative one-step extraction and clean-up method for solid samples, due

\footnotetext{
* To whom all correspondence should be addressed. 谓 +267-721-446-56; fax: +267-355-2836;

e-mail: Immualefe@gmail.com

Received 7 August 2007; accepted in revised form 15 April 2008
}

to desirable properties of supercritical fluids such as higher diffusivity, low viscosity and adjustable solvent strength which allow the selective extraction of different chemicals and the use of small sample amounts (Rissato et al., 2004).

A majority of SFE applications employ carbon dioxide $\left(\mathrm{CO}_{2}\right)$ as the solvent of choice because it is non-toxic, non-flammable, has a low critical temperature $\left(31^{\circ} \mathrm{C}\right)$ and pressure $(74 \mathrm{bar}=$ $7400 \mathrm{KPa}$ ) as well as being available at high purity (Létisse et al., 2006). The pressure and temperature of the supercritical fluid can be varied so as to effect selectivity during extraction (Fidalgo-Used et al., 2007). Even though supercritical $\mathrm{CO}_{2}$ is a good solvent only for the extraction of non-polar to moderately polar compounds, the extraction of polar compounds can be improved by the addition of small quantities of polar organic solvents employed as modifiers (Naude et al., 1998; Rial-Otero et al., 2007). Thus the optimisation of SFE parameters such as modifier, pressure and temperature is essential due to the diversity of sediment types and compositions, as well as their influence on pesticide adsorption (Gonçalves et al., 2006).

This paper presents a method that has been optimised for SFE of pesticides in sediment samples followed by gas chromatography electron capture detection (GC-ECD) and gas chromatography-time-of-flight mass spectrometry (GC-ToF-MS).

\section{Materials and method}

\section{Standards, reagents and apparatus}

$\alpha$-Benzene hexachloride ( $\alpha$-BHC) (97.9\%), $\beta$-benzene hexachloride ( $\beta$-BHC) $(98.0 \%), \gamma$-benzene hexachloride $(\gamma$-BHC, Lindane) (99.8\%), methoxychlor (98\%) and heptachlor (98.5\%) were obtained from Supelco (Bellafonte, PA, USA). Aldrin (98.1\%), 


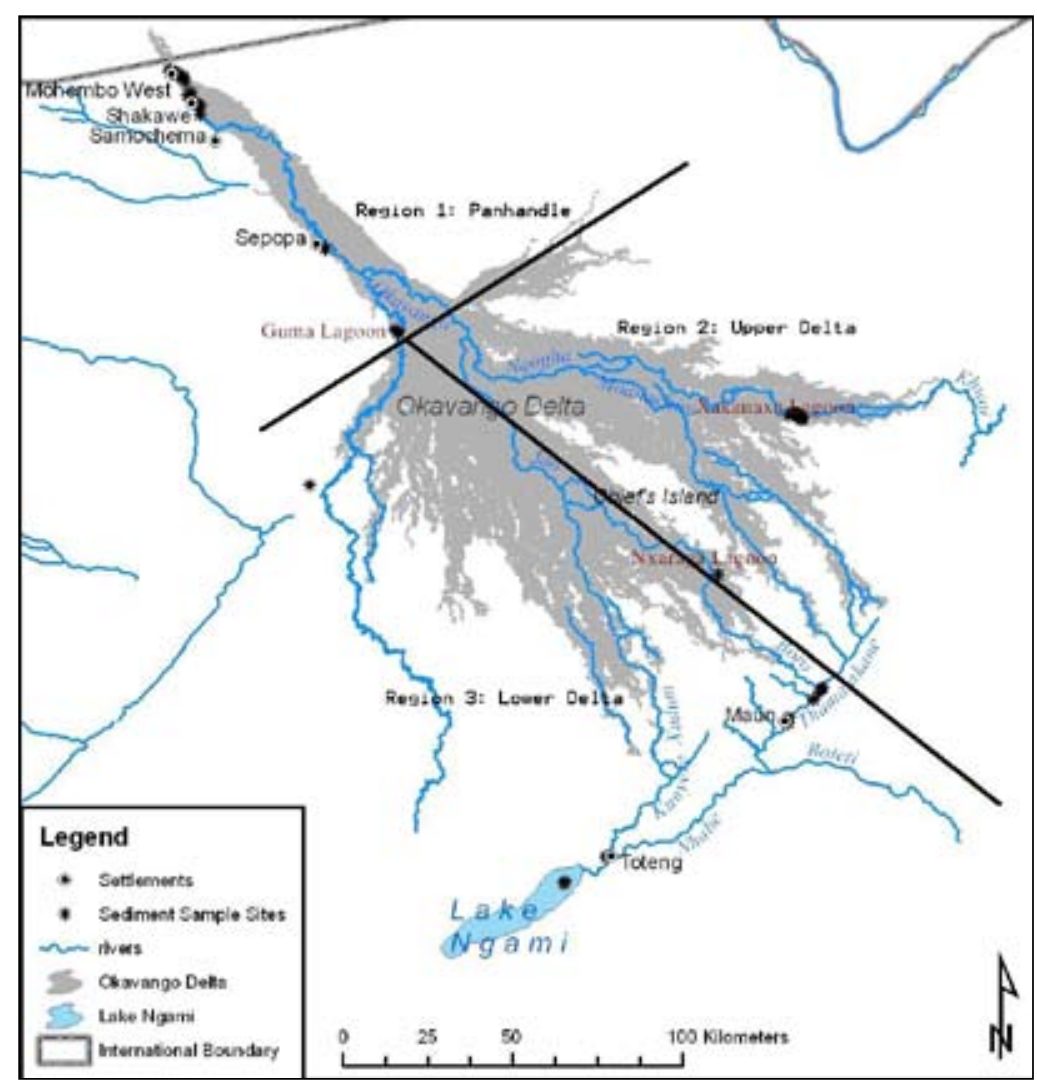

Figure 1

Map of the Okavango Delta showing sampling areas.

For ease of data analysis and interpretation samples were divided into the three regions indicated on the map.

$\mathrm{m} \times 0.25 \mathrm{~mm} \times 0.25 \mu \mathrm{m}$ (film thickness) manufactured by Phenomenex (Torrence, CA, USA) was employed in the separation of analytes. Ultra-high purity $(99.999 \%)$ nitrogen gas was used as carrier gas at a column head pressure of $96.5 \mathrm{KPa}$. The injector and detector temperatures were set to 250 and $300^{\circ} \mathrm{C}$, respectively. The oven temperature was programmed from an initial value of $50^{\circ} \mathrm{C}$ (hold $1 \mathrm{~min}$ ), ramped to $200^{\circ} \mathrm{C}$ at a rate of $40^{\circ} \mathrm{C} /$ min (hold $2 \mathrm{~min}$ ), ramped to $240^{\circ} \mathrm{C}$ at a rate of $4^{\circ} \mathrm{C} / \mathrm{min}$ (hold $1 \mathrm{~min}$ ) and finally ramped to $300^{\circ} \mathrm{C}$ at a rate of $4^{\circ} \mathrm{C} / \mathrm{min}$ (hold $5 \mathrm{~min}$ ). The injection volume was $1 \mu \ell$ in the splitless mode.

Analytes were confirmed on a $6890 \mathrm{~N}$ gas chromatograph equipped with a 7683B auto-sampler manufactured by Agilent Technologies (Shanghai, China) connected to a GCT Premier time-offlight mass spectrometer manufactured by Waters (Manchester, England). The column and oven temperature programme employed in the Pelkin Elmer GC-ECD was also used in the GC-MS. Helium was used as a carrier gas at a rate of $1 \mathrm{~m} \ell / \mathrm{min}$. The injector, and transfer line temperatures were both maintained at $250^{\circ} \mathrm{C}$ while the ion source was kept at $300^{\circ} \mathrm{C}$. The electron impact (EI) source in the positive mode was operated at $70 \mathrm{eV}$ and the mass spectra were acquired in the 50 to $500 \mathrm{~m} / \mathrm{z}$ range. The solvent delay time was set to $3.8 \mathrm{~min}$. Mass spectra were compared to the NIST/EPA/NIH Mass Spectral Library - Version 2005 (Newfield NT, USA).

\section{Study area}

trans-chlordane (99.5\%), 2, 4'-DDD (99.7\%), 4, 4'-DDD (98.9\%), 4, 4'-DDE (99.5\%), 4, 4'-DDT (99.6\%), dieldrin (97.9\%), endrin (99.1\%), $\beta$-endosulfan (99.9\%) and hexachlorobenzene (HCB) $(99.6 \%)$ were obtained from Riedel-de-Haën (Seelze, Germany). Stock solutions of each pesticide were prepared in acetone at 100 $\mu \mathrm{g} / \mathrm{m} \ell$ concentrations. A 1 to $10 \mu \mathrm{g} / \mathrm{m} \ell$ working standard mixture was prepared containing $1 \mu \mathrm{g} / \mathrm{m} \ell$ each of aldrin, $\alpha-B H C$, $\gamma$-BHC, HCB and heptachlor, $2 \mu \mathrm{g} / \mathrm{m} \ell$ each of 4,4 '-DDE and dieldrin, $3 \mu \mathrm{g} / \mathrm{m} \ell$ each of $\beta$-BHC, 4,4 '-DDT and $\beta$-endosulfan, $4 \mu \mathrm{g} / \mathrm{m} \ell$ each of 2, 4'-DDD, 4, 4'-DDD and endrin, $5 \mu \mathrm{g} / \mathrm{m} \ell$ of trans-chlordane and $10 \mu \mathrm{g} / \mathrm{m} \ell$ of methoxychlor.

HPLC grade acetone, $n$-hexane and toluene were obtained from Ultrafine Limited (London, England). Ultra-high purity (UHP) water was generated from a Millipore Alpha-Q System supplied by Millipore (Molsheim, France).

\section{Instrumentation}

Sediment samples were freeze-dried on a Modulyo 4K FreezeDryer manufactured by Edwards High Vacuum (Crawley, England). A Speed SFE instrument manufactured by Applied Separations (Allentown, PA, USA) consisting of a Speed SFE pressure regulator, Speed SFE oven and a $5 \mathrm{~m} \ell$ extraction cell was employed for analyte extraction. $\mathrm{A} \mathrm{CO}_{2}$ (industrial grade) gas cylinder $(99.8 \%)$ was connected to the pressure regulator.

Gas chromatography was performed on an Autosystem XL gas chromatograph manufactured by Perkin Elmer (Norwalk, CT, USA) equipped with a split/splitless injector, a ${ }^{63} \mathrm{Ni}$ electron-capture detector (ECD). A Zebron ZB-35 (35\% phenyl and $65 \%$ dimethylsiloxane) fused silica capillary column 30
The study area shown in Fig. 1 is the Okavango Delta that is situated between longitudes 20 to $24^{\circ} \mathrm{E}$ and latitudes 18 to $20^{\circ} \mathrm{S}$. It is a unique ecological system famous for its fauna and flora and covers an area of $28000 \mathrm{~km}^{2}$ of which $6000 \mathrm{~km}^{2}$ is permanent swamp and $12000 \mathrm{~km}^{2}$ seasonal swamp (Hutton and Dincer, 1976). Okavango sediments are predominantly fine- to medium-grain sands of aeolian origin with a minor component consisting of silts and clays. The channel sediments consist of clean sand. In drainage basins such as Lake Ngami and lagoons such as Guma Lagoon, there is a higher percentage of organic matter and silts and clays in the sediments (Huntsman-Mapila et al., 2006).

\section{Sample collection}

Sediment samples $(\sim 100 \mathrm{~g})$ were collected between September 2005 and September 2006 from Chief's Island, Guma Lagoon, Lake Ngami, Maun, Mohembo, Samochima, Sepopa, Shakawe, Toteng and Xakanaxa in the delta. The samples were wrapped in aluminium foil previously rinsed with acetone and dried under an extraction hood. The foil packages were then placed into labelled plastic bags with a tight seal and stored in ice while on the field. Upon arrival at the laboratory the samples were preserved in a cold room at $4^{\circ} \mathrm{C}$ prior to analysis due to lack of freezer space and analyses were carried out within a month.

\section{Sediment preparation}

Sediment samples were frozen in $250 \mathrm{~m} \ell$ round-bottomed flasks and lyophilised overnight to remove water. The flasks were then 
TABLE 1

Parameters of the three tested SFE settings (Note: $1 \mathrm{Bar}=100 \mathrm{KPa}$ )

\begin{tabular}{|c|c|c|c|c|c|c|c|}
\hline \multirow{2}{*}{$\begin{array}{c}\text { SFE } \\
\text { Setting }\end{array}$} & \multirow{2}{*}{$\begin{array}{c}\text { Modifier \& } \\
\text { volume }\end{array}$} & \multicolumn{2}{|c|}{ Step (i) } & \multicolumn{2}{c|}{ Step (ii) } & \multicolumn{2}{c|}{ Step (iii) } \\
\cline { 3 - 8 } & - & $400 \mathrm{bar}, 120 \mathrm{~min}$ & $5 \mathrm{~min}$ & - & - & Static & - \\
\hline 1 & - & Dynamic & - \\
\hline 2 & $\mathrm{H}_{2} \mathrm{O}, 100 \mu \ell$ & $200 \mathrm{bar}, 60 \mathrm{~min}$ & $5 \mathrm{~min}$ & $400 \mathrm{bar}, 60 \mathrm{~min}$ & $5 \mathrm{~min}$ & - & - \\
\hline 3 & Acetone, $50 \mu \ell$ & $200 \mathrm{bar}, 30 \mathrm{~min}$ & $5 \mathrm{~min}$ & $350 \mathrm{bar}, 30 \mathrm{~min}$ & $5 \mathrm{~min}$ & $400 \mathrm{bar}, 15 \mathrm{~min}$ & $5 \mathrm{~min}$ \\
\hline
\end{tabular}

removed and the sediment shaken to break lumps before being passed through a $100 \mu \mathrm{m}$ sieve to remove rocks, roots and other debris. The sediment samples were wrapped in $10 \times 10 \mathrm{~cm}$ pieces of acetone-rinsed aluminium foil, sealed in plastic bags and stored at $4^{\circ} \mathrm{C}$ for a maximum of one week.

\section{Testing of different SFE settings}

In order to reduce laborious investigations of effects of the individual parameters such as pressure, extraction time and modifier type and volume influencing recovery during SFE, three different combinations of parameters were explored. Oven and outlet valve temperatures were maintained at 60 and $100^{\circ} \mathrm{C}$, respectively. Glass wool (rinsed with acetone and dried) was placed at both ends of the extraction cell to prevent pieces of sediment being drawn into the capillaries of the instrument. The mass of sediment chosen for each extraction was $3 \mathrm{~g}$ as it left enough room for glass wool at both ends of the extraction cell. A sediment sample, dark in colour indicating high organic matter content was chosen as a 'test' sample and was employed to compare three SFE protocols.

Three different combinations of SFE parameters were investigated and are given in Table 1. For each setting of SFE parameters, three aliquots of an un-spiked sample were extracted so as to obtain background pesticides concentrations that would be subtracted from those in the spiked sample. $1000 \mu \ell$ of the 1 to $10 \mu \mathrm{g} / \mathrm{m} \ell$ standard mixture was employed for spiking each of the $3 \mathrm{~g}$ aliquots. In the first set of parameters, each of the $3 \mathrm{~g}$ aliquots was spiked, mixed and air-dried under a fume-hood prior to loading into the extraction cell. A modifier was added to each spiked aliquot for settings 2 and 3 as shown in Table 1 . The extraction cell was then placed into the SFE instrument that had been pre-set to the required conditions.

The extracts were collected in $1 \mathrm{~m} \ell$ toluene contained in 10 $\mathrm{cm} \times 1 \mathrm{~cm}$ test tubes with the tip of the outlet-valve needle just above the collection solvent. At the end of each collection the needle on the outlet valve was rinsed with $1 \mathrm{~m} \ell$ acetone. The extract in toluene was transferred to a $2 \mathrm{~m} \ell$ glass vial and evaporated completely. Analytes were reconstituted in $50 \mu \ell$ acetone and $50 \mu \ell \mathrm{n}$-hexane, mixing well after each addition and $1 \mu \ell$ injected into the gas chromatograph. Background pesticide concentrations in the un-spiked samples were subtracted from those in the spiked samples. The subsequent pesticides concentrations were compared to those in a $1000 \mu \ell$ of standard mixture that had been similarly evaporated completely and reconstituted in $50 \mu \ell$ each of acetone and n-hexane.

\section{SFE of sediment samples and analysis}

After optimisation of SFE conditions, $3 \mathrm{~g}$ sediment samples were extracted employing optimal SFE conditions and the extracts analysed by GC-ECD followed by confirmation with GC-ToFMS. After each extraction, care was taken to clean the extraction cell thoroughly with water and soap before rinsing with acetone and n-hexane. The analyses were performed in triplicate.

\section{Results and discussion}

\section{Calibration levels}

Only 3 pesticides were quantitatively determined by the external standard method employing linear calibration curves with 6 standards injected per compound. Correlation coefficients were all above 0.99 . Detection limits ranged between 0.05 and 0.31 $\mu \mathrm{g} / \mathrm{g}$. A chromatogram (GC-ECD) showing the separation of a 15-component pesticide standard mixture is captured in Fig. 2.

\section{Testing of different SFE settings}

The quantitative extraction of an analyte from a solid matrix may be viewed as a three-step process:

- Firstly, the analyte must be efficiently partitioned from the sample matrix into the extraction medium. In SFE this step is controlled by several factors such as the affinity of the analyte towards the matrix, the vapour pressure of the analytes and the solubility and diffusion coefficient of the analyte.

- Secondly, the analyte must be swept away from the extraction cell.

- Finally, it must be efficiently collected (Quan et al., 2004).

$\mathrm{CO}_{2}$ is a non-polar solvent and in the case when it is required to extract analytes such as pesticides that have a wide range of physico-chemical properties, its extraction efficiency is not satisfactory. The introduction of a modifier enhances analyte solubility, covering matrix active sites and inhibiting the desorbed analytes' re-adsorption into the matrix (Hu et al., 2007; Anitescu

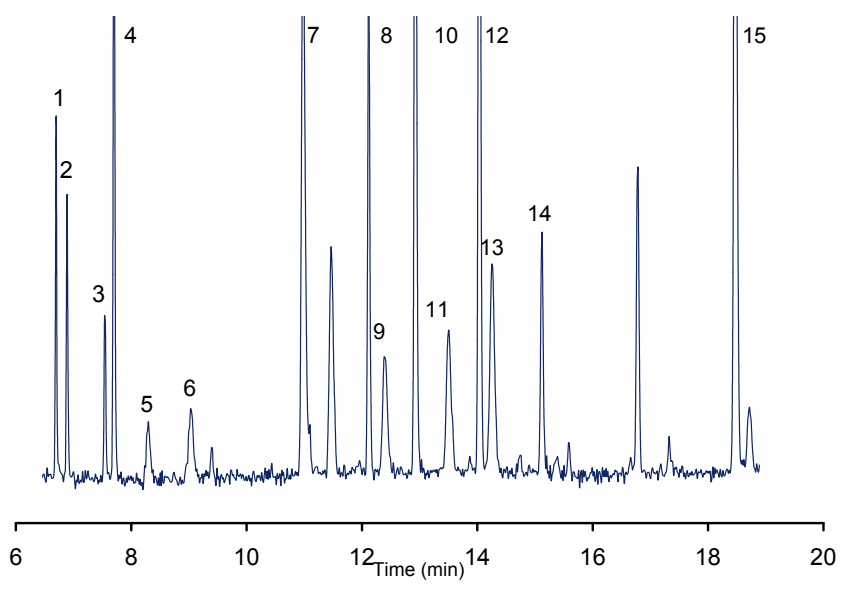

Figure 2

Chromatogram (GC-ECD) of pesticide standards mixture (1 to $10 \mu \mathrm{g} / \mathrm{ml}) .1=$ Hexachlorobenzene $(\mathrm{HCB}) ; 2=\alpha-$ Benzene hexachloride $(\alpha-B H C) ; 3=\gamma$ - Benzene hexachloride $(\gamma-B H C$, Lindane); $4=\beta$-Benzene hexachloride $(\beta-B H C) ; 5=$ Heptachlor; $6=$ Aldrin; 7 = Trans-chlordane; $8=4,4$ '-DDE; $9=$ Dieldrin; $10=2,4^{\prime}-D D D ; 11=$ Endrin; $12=4,4^{\prime}-D D D ; 13=\beta$-Endosulfan; $14=4,4^{\prime}-D D T ; 15=$ Methoxychlor. 


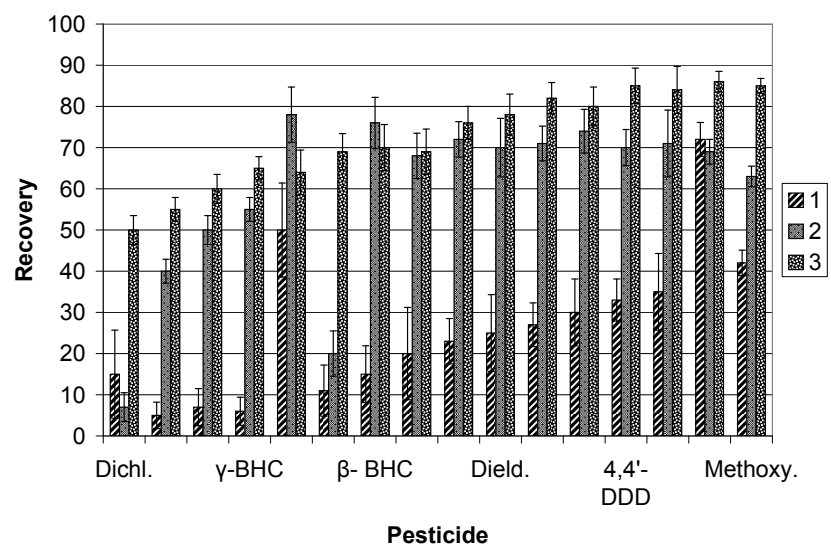

Figure 3

Recoveries of pesticides after SFE of a spiked sediment sample employing the three different settings mentioned in Table 1.

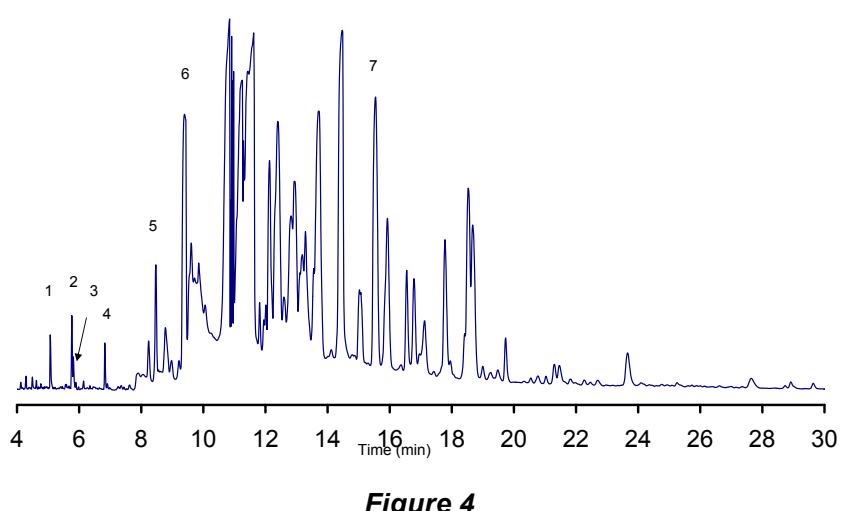

Figure 4

Total ion chromatogram of a sediment sample showing [1] hexadecane; [2] octadecane; [3] 5-octadecene; [4] HCB; [5] $\alpha$-chlordene; [6] aldrin and [7] 4,4' -DDT. The rest of the peaks could not be tentatively identified since match factors of their spectra were less than 800 in the NIST 2005 library. and Tavlarides, 2006). Evaluation of the different SFE settings showed that the use of modifier was essential. Figure 3 shows that without the addition of a modifier, pesticide recoveries were generally low, ranging from 5 and $50 \%$ except for the $75 \%$ recovery of 4, 4'-DDT. The low recoveries indicated the insolubility of the pesticides in $\mathrm{CO}_{2}$ at 400 bar (In SI please; convert to $\mathrm{Pa}$ ) while the conditions were suitable for the extraction of 4, 4'-DDT

Water is suspected to favour swelling of the matrix thereby enhancing diffusion of the fluid inside the matrix (Nemoto et al., 1997). It was, however, observed that pesticide recoveries with a water modifier were generally lower than when acetone was employed except for heptachlor and $\beta$-BHC. SFE extracts in which acetone was employed as a modifier had an intense green colour probably due to co-extraction of organic matter in the sediment matrix by acetone.

Raising the extraction pressure at constant temperature leads to a higher fluid density that increases the solubility of analytes (Ghasemi et al., 2007; Camel, 1998). Ramping of pressure or fractional extraction was employed as suggested by Reverchon and De Marco (2006) resulting in recoveries ranging from 55 to $86 \%$ with HCB being the least recovered and 4,-4'-DDT the most recovered pesticide. The recovery of $\mathrm{HCB}$ at $55 \%$ was judged acceptable given that most pesticides had recoveries higher than $70 \%$. Thus the optimised SFE conditions that were employed for the extraction of pesticides in sediment samples were $50 \mu \ell$ of acetone, 200 bar (30 min static), 350 bar (30 min static), 400 bar $(15 \mathrm{~min}$ static) (Note: 1 bar $=100 \mathrm{KPa})$. Dynamic extraction for 5 min was carried out after every static extraction.

\section{SFE of sediment samples and analysis}

Sediment samples were extracted employing the SFE optimised conditions.. Four pesticides, namely, aldrin, $\alpha$-chlordene, HCB and 4,4'-DDT as well as hydrocarbons such as hexadecane, octadecane and 5-octadecene were tentatively identified by mass spectrometry as shown in
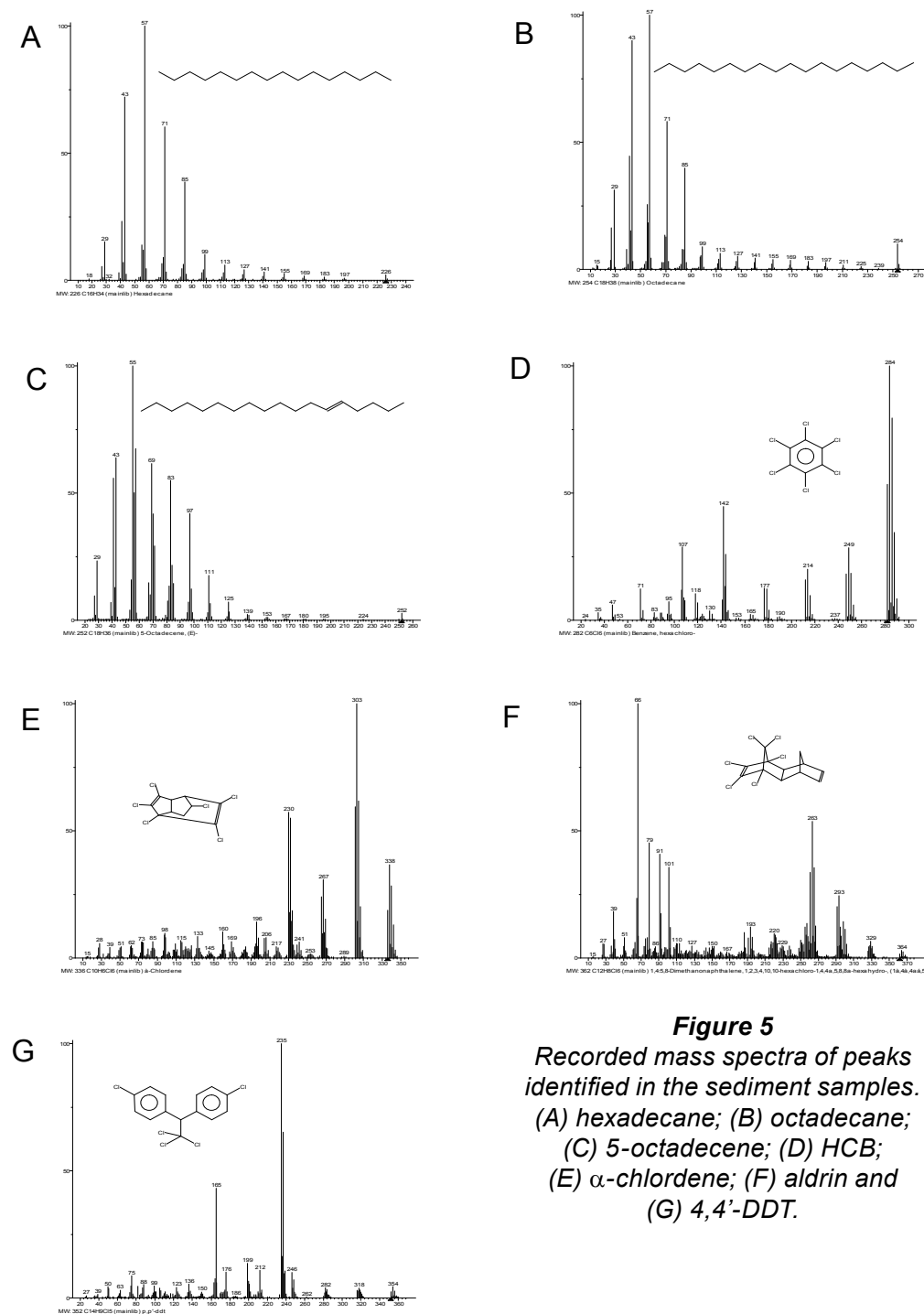

Figure 5

Recorded mass spectra of peaks identified in the sediment samples. (A) hexadecane; (B) octadecane; (C) 5-octadecene; (D) HCB;

(E) $\alpha$-chlordene; (F) aldrin and (G) $4,4^{\prime}-D D T$.

Fig. 4. The mass spectra of the same compounds are shown in Fig. 5. However, only aldrin, HCB and 4,4'-DDT could be quantified due to lack of pure chemical standards for the other compounds. Concentrations of $\mathrm{HCB}$, ranged from 1.1 to $30.3 \mu \mathrm{g} / \mathrm{g}$ while those of aldrin and 4,4' to DDT ranged from $0.5-15.2$ and 1.4 to $55.4 \mu \mathrm{g} / \mathrm{g}$, respectively. For simplicity of data analysis, the sampling area was divided into 3 regions 
and the mean concentration of each pesticide calculated for each region:

- Region 1 (the Panhandle) consisting of samples from Mohembo, Shakawe, Samochima, Sepopa and Guma Lagoon

- Region 2 (the upper delta) consisting of samples from Chief's Island and Xakanaxa

- Region 3 (the lower delta) consisting of samples from Lake Ngami, Maun and Toteng.

The distribution of pesticides in sediments from the 3 regions revealed an accumulation pattern as shown in Fig. 6. Sediments from Region 1 (the Panhandle) contained the lowest mean concentrations of pesticides ranging from 1 to $4 \mu \mathrm{g} / \mathrm{g}$ while sediments from Region 3 had the highest mean concentrations ranging from 8 to $45 \mu \mathrm{g} / \mathrm{g}$. This trend may be due to the direction of flow of the water as well as the low topographic gradient of the Delta causing low flow rates (Andersson et al., 2003). The low flow rates allow partitioning of water insoluble components such as pesticides onto suspended matter that subsequently settles to the bottom of the river becoming part of sediment. Thus pesticides are more likely to be adsorbed onto organic-rich sediment as compared to the sandy sediment such as characteristic of the Panhandle as reported by Daka et al. (2006).

HCB and aldrin are employed in agriculture as a dressing for seed grains due to their effectiveness against various pests and may be transported into rivers by water run-off. They are insoluble in water but readily adsorbed onto soils and sediments (Yuan et al., 2006). DDT has been employed for aerial spraying by the public health authorities in the study area from the $1940 \mathrm{~s}$ until the late 1990s (Mabaso et al., 2004), hence its presence in sediments is not surprising. However, the presence of 4, 4'-DDT at elevated levels in sediments at the peripheries of the delta may be due to the fact that these areas act as final catchments for the water. Lake Ngami, for example, is at the receiving end of the delta and is not fed by any other water source. The sediments in these areas are rich in organic matter, accumulating considerable amounts of pesticides by adsorption. Alternatively, there could be an illegal input of pesticides employed on vegetable farming taking place on the peripheral areas of the delta. Similar observations were made by Sereda and Meinhardt (2005) in their study of water and sediments in KwaZulu-Natal, South Africa whereby the highest polluted areas were those where vegetable production occurred.

\section{Conclusions}

SFE conditions were optimised for pesticides in sediments from the Okavango Delta. An acetone modifier and fractional extraction by pressure ramping gave the highest recoveries ranging from 55 to $86 \%$ for the 15 pesticides studied. Lowest pesticide concentrations were observed in sediments from the Panhandle while the highest concentrations were observed in samples from the lower Delta. This indicated a possible cumulative effect of pesticides in the direction of water flow from the Panhandle to the lower Delta. The change of sediment type from sandy in the Panhandle to organic-rich clay in the lower delta may also have influenced the pesticide storage capacity of the sediments. Alternatively there could be a current input of pesticides from agricultural activities in the areas surrounding the lower delta. Further work will involve evaluation of a broader spectrum of contaminants in the same matrix in biota as well as investigation of possible point sources.

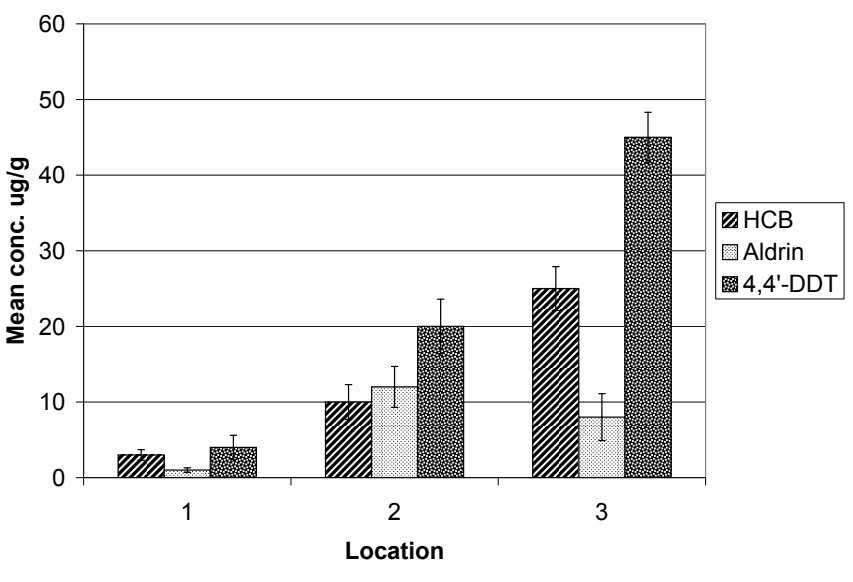

Figure 6

Mean concentrations of pesticides in sediment samples from the three regions of the Okavango Delta that were studied: (1) the Panhandle; (2) the upper Delta and (3) the lower Delta.

\section{Acknowledgements}

The authors highly appreciate financial support from the United Nations Development Program - Global Environmental Fund (UNDP-GEF) Project No. BOT/98/G52/05/04. The Department of Chemistry, University of Botswana main campus as well as the Harry Oppenheimer Okavango Research Centre (HOORC) are also acknowledged for the technical assistance. Masego Dhliwayo is thanked for his cartographic input.

\section{References}

ANDERSSON L, GUMBRICHT T, HUGHES D, RINGROSE D, KNIVERTON D, SAVENJI H, TODD M, WILK J and WOLSKI P (2003) Water flow dynamics in the Okavango River Basin and Delta - a prerequisite for the ecosystems of the Delta. Phys. Chem. Earth 28 1163-1172.

ANITESCU G and TAVLARIDES LL (2006) Supercritical extraction of contaminants from soils and sediments. J. Supercrit. Fluid. $\mathbf{3 8}$ (2) $167-180$.

CAMEL V (1998) Supercritical fluid extraction as a useful method for pesticides determination. Analusis 26 (6) 99-111.

DAKA PS, OBUSENG VC, TORTO N and HUNTSMAN-MAPILA P (2006) Deltamethrin in sediment samples of the Okavango Delta, Botswana. Water SA 32 (4) 483-488.

DELISTRATY D and YOKEL J (2007) Chemical and ecotoxicological characterization of Columbia River sediments below the Hanford site (USA). Ecotoxicol. Environ. Saf. 66 16-28.

FIDALGO-USED N, BLANCO-GONZÁLEZ E and SANZ-MEDEL A (2007) Sample handling strategies for the determination of persistent trace organic contaminants from biota samples. Anal. Chim. Acta 590 1-16.

GABALDÓN JA, MAQUIEIRA A and PUCHADES R (2007) Development of a simple extraction procedure for chlorpyrifos determination in food samples by immunoassay. Talanta 71 1001-1010.

GHASEMI E, YAMINI Y, BAHRAMIFAR N and SEFIDKOU F (2007) Comparative analysis of supercritical $\mathrm{CO}_{2}$ extract of Artemisia sieberi. J. Food Eng. 79 (1) 306-311.

GONÇALVES C, CARVALHO JJ, AZENHA MA and ALPENDURA MF (2006) Optimisation of supercritical fluid extraction of pesticide residues in soil by means of central composite design and analysis by gas chromatography-tandem mass spectrometry. J. Chromatogr. A 1110 6-14.

GUEVARA-RIBA A, RUBIO R, RAURET G, MUNTAU H and SAHUQUILLO A (2006) Method study for the preparation of a wet sediment quality control material. Anal. Chim. Acta 555 384-390.

HUNTSMAN-MAPILA P, MAPILA T, LETSHWENYO M, WOLSKI $P$ and HEMOND C (2006) Characterisation of arsenic occurrence 
in the water and sediments of the Okavango Delta, NW Botswana. Appl. Geochem. 21 1376-1391.

HU Q, PAN B, XU J, SHENG J and SHI Y (2007) Effects of supercritical carbon dioxide extraction conditions on yields and antioxidant activity of Chlorella pyrenoidosa extracts. J. Food Eng. 80 997-1001.

HUTTON LG and DINCER T (1976) Investigation of the Okavango Delta as a Primary Water Resource for Botswana. Technical Note 23, UNDP:FAO.AG:DP/BOT/71/506.

LÉTISSE M, ROZIÈRES M, HIOL A, SERGENT M and COMEAU L (2006) Enrichment of EPA and DHA from sardine by supercritical fluid extraction without modifier: I. Optimisation of extraction conditions. J. Supercrit. Fluid. 38 27-36.

MABASO MLH, SHARP B and LENGELER C (2004) Historical review of malarial control in southern Africa with emphasis on the use of indoor residual house spraying. Trop. Med. Int. Health 9 846-856.

NAUDE Y, DE BEER WHJ, JOOSTE S, VAN DE MERWE L and VAN RENSBURG SJ (1998) Comparison of supercritical fluid extraction and Soxhlet extraction for the determination of DDT, DDD and DDE in sediment. Water SA 24 (3) 205-214.

NEMOTO S, SASAKI S, TOYODA M and SAYITO Y (1997) Effect of extraction conditions and modifiers on the supercritical fluid extraction of 88 pesticides. J. Chromatogr. Sci. 35 (10) 467-477.

QUAN C. LI S, TIAN S, XU H, LIN A and GU L (2004) Supercritical fluid extraction and clean-up of organochlorine pesticides in ginseng. J. Supercrit. Fluid. 31 (2) 149-157.
REVERCHON E and DE MARCO I (2006) Supercritical fluid extraction of natural matter. J. Supercrit. Fluid. 38 (2) 146-166.

RIAL-OTERO R, GASPAR EM, MOURA I and CAPELO JL (2007) Chromatographic-based methods for pesticide determination in honey- An overview. Talanta 71 503-514.

RISSATO SR, GALHIANE MS, KNOLL FRN and APON BM (2004) Supercrtical fluid extraction of pesticide multiresidue analysis in honey: determination by gas chromatography with electron capture and mass spectrometric detection. J. Chromatogr. A 1048 153-159.

RODIL R, CARRO AM, LORENZO RA and CELA R (2007) Multicriteria optimisation of a simultaneous supercritical fluid extraction and clean-up procedure for the determination of persistent organohalogenated pollutants in aquaculture simples. Chemosphere 67 (7) 1453-1462.

SANTOS FJ and GALCERAN MT (2002) The application of gas chromatography to environmental analysis. TrAC Trends Anal. Chem. 21 (9-10) 672-685.

SEREDA L and MEINHARDT HR (2005) Contamination of the water environment in malaria endemic areas of KwaZulu-Natal, South Africa, by agricultural insecticides. Bull. Environ. Contam. Toxicol. 75 530-537.

YUAN S, TIAN M and LU X (2006) Electrokinetic movement of hexachlorobenzene in clayed soils enhanced by Tween 80 and $\beta$-cyclodextrin. J. Hazard. Mater. B137 1218-1225.

ZHAO G, XU L, LI W, HAN G and LING B (2007) PCBs and OCPs in human milk and selected foods from Luquiao and Pingquiao in Zhejiang, China. Sci. Total Environ. 378 281-292. 